www.jmscr.igmpublication.org

Index Copernicus Value: 79.54

ISSN (e)-2347-176x ISSN (p) 2455-0450

crossref DOI: https://dx.doi.org/10.18535/jmscr/v7i4.75

$\underline{\text { Research Article }}$

\title{
Assessment of incidence and severity of adverse drug reactions in multidrug resistant tuberculosis patients
}

\author{
Authors \\ G.Akhil $^{1}$, T.Hussain Naik ${ }^{1}$, Dr P.Manjula ${ }^{1}$, G. Nikhitha $^{1^{*}}$ \\ ${ }^{1}$ Department of Pharmacy Practice, CARE College Of Pharmacy, Oglapur (V), Damera (M), Warangal \\ Rural, Telangana-506006, India \\ *Corresponding Author \\ G. Nikhitha \\ Email: Nikhithagandhe@gmail.com, Mobile: 8179439290
}

\begin{abstract}
281 patients who were diagnosed as MDR-TB by Department of Chest disease and Tuberculosis hospital, Hanamkonda were enrolled in the study over a period of January 2016 to may 2018. Detection and monitoring of ADR was done by interviewing patient and reviewing laboratory tests on monthly basis till their ATT continued. Patients were instructed to report any sign and symptoms they come across during the treatment period. A total of 317 ADRs were detected, documented, assessed and reported during the study period. The causality assessment of ADRs reveled that most of the ADRs were "possible" in nature. Assessment of severity of the suspected ADRs revealed that $35.78 \%$ of suspected ADRs were mild and $51.38 \%$ of ADRs were moderate in severity. Early detection, management and reporting of ADRs remain key factors in the management of MDR-TB with remarkable relevance to prevent emergence threat of global MDR-TB.

Keywords: Multi drug resistant tuberculosis, adverse dug reaction, anti tubercular therapy.
\end{abstract}

\section{Introduction}

Multidrug resistant tuberculosis (MDR-TB), defined as resistance to at least rifampicin and isoniazid, is a growing concern throughout the world. As per recent global tuberculosis report of WHO the incidence of MDR-TB is 3.5\% among new cases and $20.5 \%$ among previously treated for tuberculosis cases. India along with China \& Russian Federation contributes to about half the load of MDR-TB cases ${ }^{[1]}$.

According to $\mathrm{WHO}$, adverse drug reaction is defined as "any response to a drug which is noxious \& unintended \& which occurs at doses normally used in man for prophylaxis, diagnosis or therapy of disease or for the modification of physiological function." like many other drug, antitubercular drugs also cause various types of adverse drug reactions and affects almost all the system in the body mainly the gastrointestinal, liver, skin, nervous system and eyes ${ }^{[2]}$. There adverse drug reactions prove to be a challenge to successful treatment of active patients as they are the prime factors of non adherence leading to therapeutic failure ${ }^{[3]}$. Adverse drug reactions are the leading cause of mortality and morbidity in health care and have a significant economic impact on health care resources. Serious adverse drug reactions account for $6.7 \%$ of all hospital 
admissions and occur in 10 to $20 \%$ of hospitalized patients. The impact and management of adverse drug reactions is complex as they may increase cost due to frequent hospitalization, prolongation of hospital stay, additional investigations and drug therapy in more serious cases.

Various studies have shown that adverse drug reactions to anti tubercular drugs can negatively affect the compliance, Discontinuation of treatment abruptly can indirectly contribute to multi drug resistance hence monitoring and reporting of ADRs is very much essential so that the drug causing adverse drug reactions can be identified and appropriate therapeutic regimen can be tailored to the patient. Pharmacovigilance of anti tubercular drugs is very much essential for successful treatment of tuberculosis and its elimination $^{[4,5] \text {. }}$

\section{Methodology}

A prospective, observational study was conducted among patients admitted during period 2016 January to 2018 May in the DR TB centre, Department of Pulmonary Medicine, Govt. CD \& TB Hospital, Hanamkonda.

\section{Patient eligibility}

MDR-TB case: A TB patient whose sputum is culture positive for Mycobacterium tuberculosis and is resistant in-vitro to Isoniazid and Rifampicin with or without other anti-tubercular drugs based on DST results.

\section{Inclusion Criteria}

$\checkmark \quad$ All adult patients with 18 years of age and above.

$\checkmark$ According to PMDT guidelines laid by RNTCP, all culture and DST, molecular method 9 LPA, CB- NAAT) confirmed cases of MDR-TB.

\section{Exclusion Criteria}

$\checkmark$ MDR TB with HIV positive.

$\checkmark$ Pregnant women.

$\checkmark$ XDR TB cases

$\checkmark$ Patients who already encountered ADRs with CAT1 and CAT2 drugs.

\section{Study Design}

It is a Prospective, Observational study design performed over a period from 2016 January- 2018 may and the patients included are treated with the RNTCP Regimen for MDR TB. The main goal of the study is to know the incidence and prevalence of MDR-TB in Warangal region and to assess adverse drug reactions and treatment outcomes.

\section{Results}

The study "Prevalence of adverse drug reaction in multi drug resistant tuberculosis was conducted at Government tuberculosis and chest disease hospital, Warangal. A total number of 281 patients were included in study.

\section{Distribution according to gender}

Table: 1 Gender wise distribution of MDR-TB patients:

\begin{tabular}{ccc}
\hline Gender & Number & Percentage (\%) \\
\hline Male & 215 & 76.5 \\
Female & 66 & 23.48 \\
\hline
\end{tabular}

Out of the 281 patients, $215(76.5 \%)$ were males remaining $66(23.48 \%)$ were female patients. Male patients $(76.5 \%)$ were more suffering with MDR-TB than female patients who were visiting hospital was observed at our site. This state's prevalence of MDR-TB is more in males than in females in the study population.

Table 2: Age wise distribution of MDR-TB patients

\begin{tabular}{lcc}
\hline Age $($ yrs $)$ & Number & Percentage \\
\hline$<\mathbf{2 0}$ & 23 & $8.18 \%$ \\
$\mathbf{2 1 - 4 0}$ & 138 & $49.11 \%$ \\
$\mathbf{4 1 - 6 0}$ & 92 & $32.74 \%$ \\
$\mathbf{6 1 - 8 0}$ & 28 & $9.96 \%$ \\
\hline
\end{tabular}

In this 21-40 age group (49.11\%) are more prevalent for MDR-TB followed by 41-60 age group (32.74\%), 61-80 age group ( 9.96\%) and then $<20$ age group $(8.18 \%)$.

In our study maximum cases were among the age group 21-40 years, followed by 41-60 years age group, which calls for concern 20 to 60 years is the most productive age for a person and the cases found were mostly in that age. This shows that the disease not only affects the individual but also affects the productivity of the society. 
Table: 3 Distribution of patients with co-morbid conditions

\begin{tabular}{lcc}
\hline Co-morbid condition & Number & Percentage \\
\hline AIDS & 20 & $7.11 \%$ \\
DM & 7 & $2.49 \%$ \\
HIV \& DM & 4 & $1.42 \%$ \\
\hline
\end{tabular}

Among co morbid conditions AIDS was seen in

20 patients, which is self explanatory. A low immunity in the patient was either the cause of the effect.

Table 4: Distribution of MDR-TB patients according to social habits

\begin{tabular}{lcc}
\hline Social habit & Number & Percentage \\
\hline Smoker & 67 & $23.8 \%$ \\
Ex-smoker & 97 & $34.51 \%$ \\
Alcoholic & 85 & $30.24 \%$ \\
Ex-alcoholic & 84 & $29.89 \%$ \\
$\begin{array}{l}\text { Both smoker and } \\
\text { alcoholic }\end{array}$ & 66 & $23.48 \%$ \\
\hline
\end{tabular}

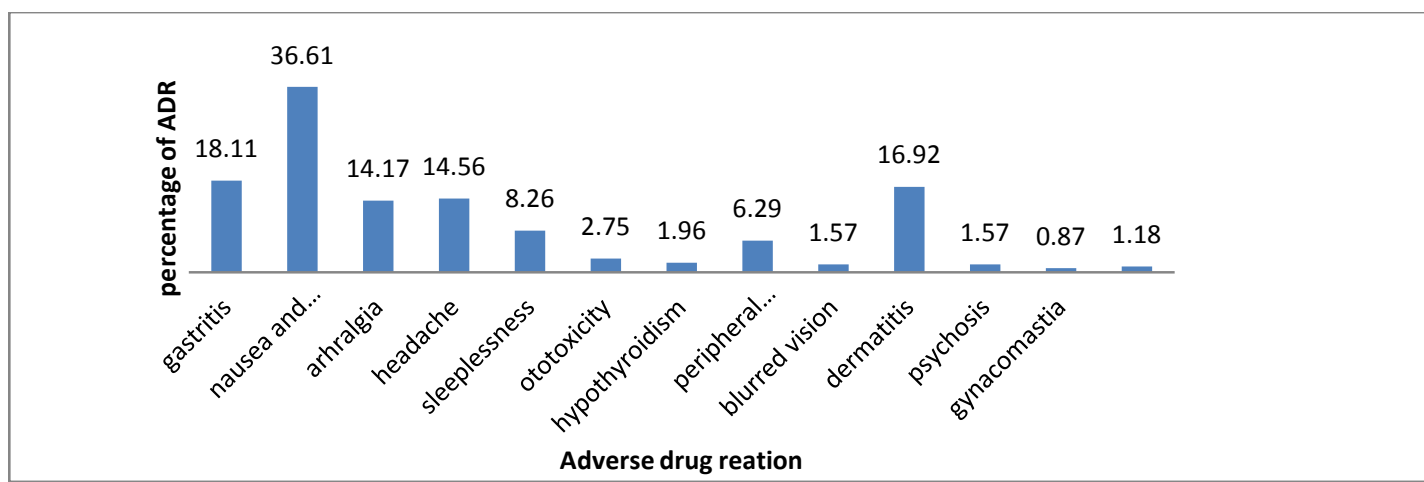

Figure 1: Prevalence of ADRs in MDR-TB

Among 254 patients in the study 317 ADRs were observed and nausea and vomiting $(36.61 \%)$ were most prevalent followed by gastritis and dermatitis. Gynacomastia (0.87\%) was less prevalent.

Table: 5 Prevalence of ADRs in age groups

\begin{tabular}{ccccc}
\hline Age group & $<\mathbf{2 0}$ & $\mathbf{2 1 - 4 0}$ & $\mathbf{4 1 - 6 0}$ & $\mathbf{6 1 - 8 0}$ \\
\hline ADRs (\%) & 11.27 & 44.85 & 39.8 & 4.23 \\
\hline
\end{tabular}

Among 281 patients 254 people were included in study. The study population was divided into various age groups. It was observed that, in the age group of 21-40 years most of the patients (44.85\%) were suffering from MDR-TB followed by $41-60$ years ( $39.8 \%$ ), age group of $>20$ years $(11.27 \%)$ and $61-80$ years $(4.23 \%)$.
Out of 281 patients in study population, we found patients who having the habit of smoking in the past accounted for $34.51 \%$ where as smoking and alcoholism were found to be in $23.8 \%$ and $30.24 \%$ respectively. $23.48 \%$ patients were found to be having both alcoholic and smoking habits. The data supports the fact that smoking and alcoholism are risk factors for many disease in the present time.

\section{Distribution adverse drug reactions}

Out of 254 patients 317 ADRs were observed in $225(88.58 \%)$ patients, remaining (11.41\%) were not affected with any ADRs.

\section{Adverse drug reactions according to organ system}

Classification of ADRs which were identified according to the organ system affected.

Table: 6 System wise distribution of ADRs

\begin{tabular}{lcc}
\hline System nervous & ADRs & $\begin{array}{c}\text { Frequency of } \\
\text { ADRs (\%) }\end{array}$ \\
\hline $\begin{array}{l}\text { Central } \\
\text { system }\end{array}$ & $\begin{array}{c}\text { Psychosis, } \\
\text { headache, } \\
\text { insomnia, } \\
\text { peripheral } \\
\text { neuropathy }\end{array}$ & $81(25.55 \%)$ \\
& $\begin{array}{c}\text { Gastritis, nausea } \\
\text { vomiting }\end{array}$ & $139(43.89 \%)$ \\
$\begin{array}{l}\text { Gastro intestinal } \\
\text { system }\end{array}$ & $\begin{array}{c}\text { Hearing loss } \\
\text { Oto -rhino- } \\
\text { vestibular }\end{array}$ & $7(2.20 \%)$ \\
$\begin{array}{l}\text { Skeletal system } \\
\text { Dermatological }\end{array}$ & $\begin{array}{c}\text { Arthralgia } \\
\text { Endocrinology }\end{array}$ & $\begin{array}{c}\text { Hypothyroidism }, \\
\text { gynacomastia }\end{array}$ \\
Ophthalmology & Blurred vision & $43(11.35 \%)$ \\
\hline
\end{tabular}




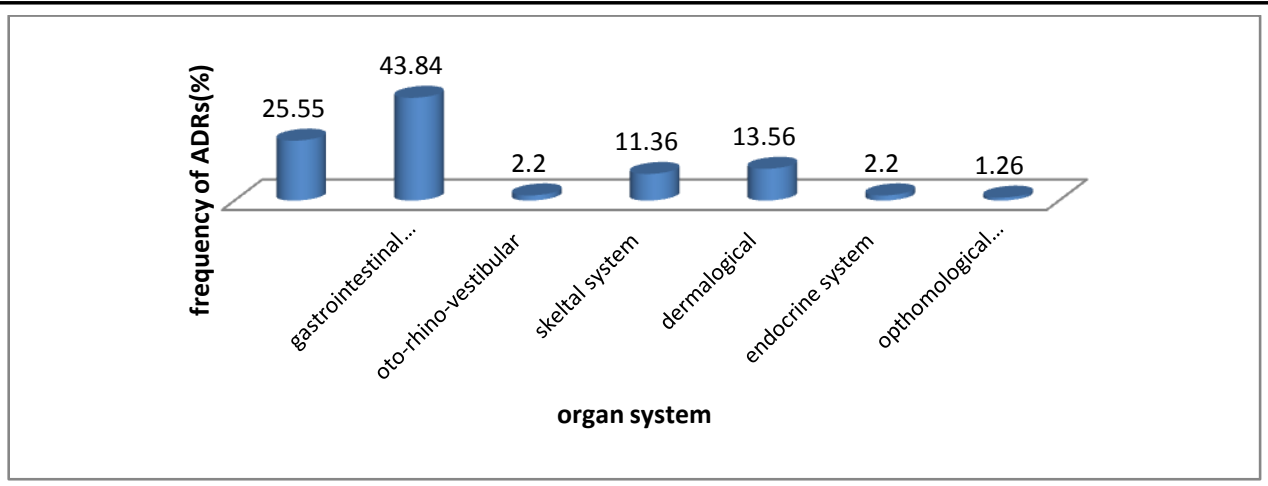

Figure 2: organ system distribution of ADRs

Among 317 ADRs in the study gastrointestinal system effects $(43.89 \%)$ were more followed by central nervous system effects $(25.55 \%)$. Then dermatological effects and skeletal effects $13.56 \%$ and $11.35 \%$ respectively were observed. Otorhino-vestibular and endocrinological effects were $2.20 \%$ and opthomological effects $1.26 \%$ were observed.
Distribution of ADRs according to causality assessment scales

Table 7: WHO causality assessment of ADRs

\begin{tabular}{llll}
\hline & \multicolumn{3}{c}{ Who scale } \\
\hline & Certain & Possible & Probable \\
ADRs & $\mathbf{3 7}$ & $\mathbf{2 3 4}$ & $\mathbf{4 6}$ \\
Percentage & $11 \%$ & $73 \%$ & $14 \%$ \\
\hline
\end{tabular}

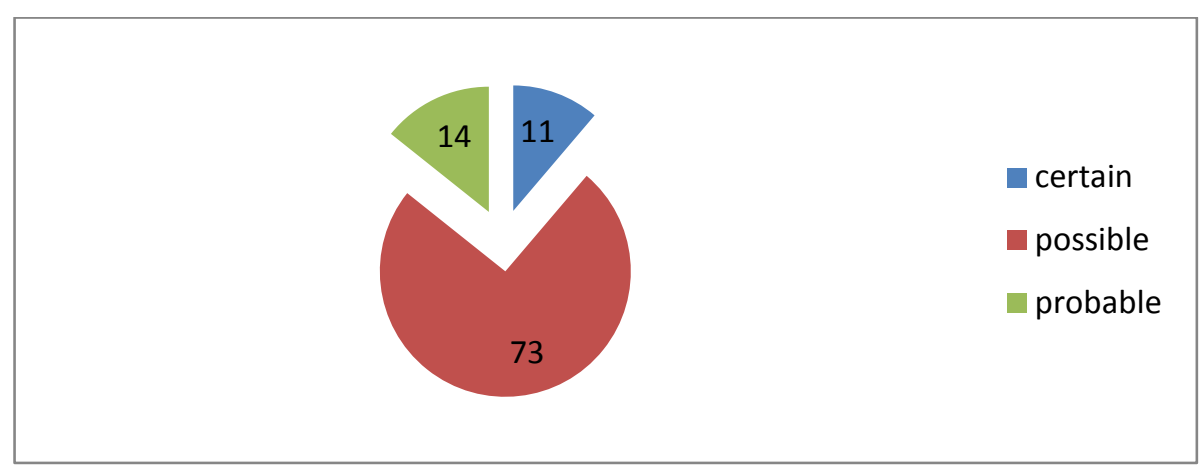

Figure 3: WHO causality assessment of ADRs

Among 317 ADRs in the study $11 \%$ were certain, $73 \%$ were possible reactions and $14 \%$ were probable reactions.

Table 8: naranjo's causality assessment

\begin{tabular}{lccc}
\hline ADRs & Definite & Probable & Possible \\
\hline Total & $\mathbf{1 1}$ & $\mathbf{7 9}$ & $\mathbf{2 2 7}$ \\
Percentage & $\mathbf{3 . 4 7}$ & $\mathbf{2 4 . 9 2}$ & $\mathbf{7 1 . 6}$ \\
\hline
\end{tabular}

According to naranjo's causality assessment scale among 317 ADRs $3.47 \%$ was definite reactions, $24.92 \%$ were probable reactions and $71.6 \%$ were possible reactions.

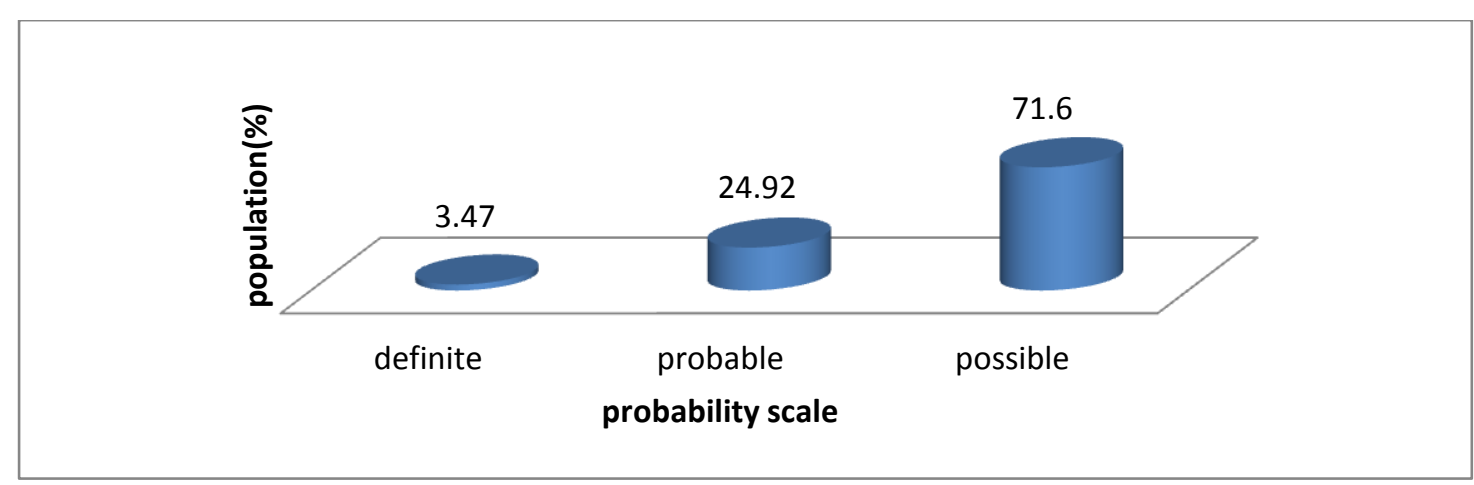

Figure 4: naranjo's probability scale 
Table 9: Hartwig and siegel severity assessment

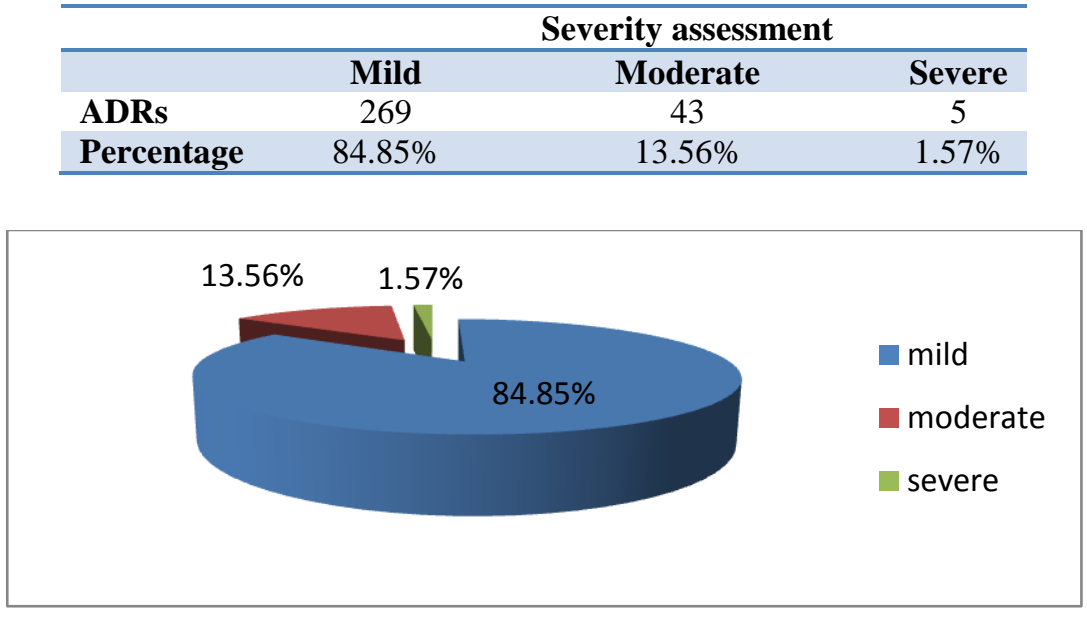

Figure 5: Hartwig and siegel severity assessment

According to Hartwig et, al severity assessment among 317 ADRs, $84.85 \%$ were mild ADRs, $13.56 \%$ were moderate ADRs and $1.57 \%$ were severe ADRs.

\section{Discussion}

In our study 281 patients were under RNTCP Warangal from January 2016 to may 2018, out of which 215 were males and 66 were females. A study conducted by (Vishaka et al., 2016) ${ }^{[6]}$ also reported high percentage of male patients $63.49 \%$ than female patient $36.51 \%$. Similarly study done by (Patil et al., 2017) ${ }^{[7]}$ also high percentage of males $61.32 \%$ than females $38.61 \%$. All these studies indicated that males are more affected than females probably due to the fact that out societal structure is such that smoking one major risk factor for TB is more prevalent in males. Also males spend more time outdoors where possibility of their coming is close contact with carriers is more when compared to females who spend less time outdoors. In this study most patients were in the age group of $21-40$ years $(49.11 \%)$ followed by $41-60$ years $(32.74 \%)$. Similar study conducted by (Vardhan et al., 2016) ${ }^{[8]}$ also reported that age group of 21-40 years (62\%) were more affected followed by 41-60 years (17\%). This shows an alarming trend because 20 to 60 years is the most productive age for a person and the cases found were mostly in that age. This shows that the disease not only affects the individual but also affects the productivity of the society. In our study
27 patients were presented with co-morbid conditions like AIDS and diabetes mellitus. In them $7.11 \%$ were with AIDS, $2.49 \%$ were with DM and remaining $1.41 \%$ were with both AIDS \& DM. Among co-morbidities AIDS was seen in 20 patients, which is self explanatory. A low immunity in the patient was either he cause or the effect.

In our study $36.61 \%$ ADR's were nausea \& vomiting which is similar to $33.96 \%$ in study conducted by (Rathod K.B et al., 2015) ${ }^{[9]}$, which is less $71.1 \%$ compared in the study conducted by (Akshata et al., 2015) ${ }^{[10]}$, Gastritis was $18.11 \%$ observed which is similar to the study conducted by $14 \%$ (Akshata et al., 2015) ${ }^{[10]}$. In our study musculoskeletal system ADR's $14.17 \%$ were observed. In study conducted by (C.zala et al., $2015)^{[12]} 14.17 \%$ of ADR's were musculoskeletal system affected $10 \%$ of skeletal system ADR's observed in study conducted by (Vardhan et al., 2016) ${ }^{[8]}$ Hearing loss $2.75 \%$ was observed in our observational study. Whereas similar study was conducted by (Akshata et al., 2015) ${ }^{[10]} 3 \%$ observed where as in study conducted by $2.99 \%$ (Patil et al., 2016) ${ }^{[7]}$. In our study endocrinological effects $2.20 \%$ were observed. Whereas similar study done by (Neeta P.N et al., 2016) ${ }^{[11]}$ was found to be $2.3 \%$ and study done by (Patil et al., $2016)^{[7]}$ was $1.83 \%$. In our study dermatitis was found to be $15.92 \%$. This is more than studies conducted by (Akshata et al., 2016) and (Rathod P.N et al., $)^{[10,9]} 4.3 \%$ and $2.64 \%$ respectively. In 
our study physcosis was found to be $1.57 \%$ where as $1.6 \%$ was to be found in (Akshata et al., 2016) [10].

In present study $73 \%$ of ADR,s were possible $14 \%$ were probable and $11 \%$ were certain according to WHO causality assessment whereas similar study was conducted by (Zala et al., 2015) ${ }^{[12]}$ found to be $12.4 \%$ were possible reactions $26.45 \%$ probable \& $61.16 \%$ were certain which are different from present study because of different types ADR's were observed. In our study 71.65 were possible $24.92 \%$ were probable $\& 3.47 \%$ were definite reactions according to naranjo's causality assessment scale. Whereas study conducted by (Shinde MP et al., 2017) ${ }^{[13]}$ was observed to be $39.45 \%$ were probable $\% 60.55$ were possible which are equal to our study where as it is different from results which are observed in the study done by (C.Zala et al., 2015) ${ }^{[12]}$ found to be $57.85 \%$ were definite $26.48 \%$ were probable $9.09 \%$ were possible. In the present study severity of ADR's were found to be $84.85 \%$ were mild, $13.56 \%$ were moderate and $1.57 \%$ was severe. Where as in our study conducted by (Shinde M P et al., 2017) ${ }^{[13]}$ was found to be $35.78 \%$ were mild $51.38 \%$ were moderate, $12.84 \%$ severe. This difference was observed because of different types of ADR's.

\section{Conclusion}

The current study shows the incidence of adverse drug reactions in patients receiving anti tubercular drug therapy. Gastrointestinal system was the most common system involved in causing adverse drug reactions. The reactions may range from inconsequential to severe and may be caused by medications other than those prescribed for TB drugs. The severity level of assessment of the adverse drug reactions observed in the study showed that most of them were 'mild' in nature as per the Hart wig and siegel severity assessment scale. The causality assessment by using WHO causality assessment scale and Naranjo's probability scale showed that majority of adverse drug reactions were 'possible' relationship with suspected drugs. So, to have highest likelihood of success, chemotherapy must be provided within clinical and social framework based on individual patient needs. The study results provide an insight to the health care providers on the importance of monitoring and reporting of adverse drug reactions in patients with tuberculosis who might suffer significant deleterious effects associated with drugs. The clinical pharmacist involvement helps in detecting and monitoring of adverse drug reactions that might help to improve the patient adherence, reduce mortality and obtain better treatment outcomes.

\section{References}

1. WHO Global Tuberculosis Report 2016

2. Honnaddi UC, Honnaddi MU, Tharangini SR, Hossain T, Somani R. Adverse Drug Reactions to First Line Anti-Tubercular Drugs-A Pharmacovigilance Study. IJPR, 2016; 6(2):51-54.

3. Mishra S, Jena M, Jena B, Mishra SS. A study of Anti-tubercular drug induced adverse drug reactions in patient's pulmonary medicine department of a tertiary care teaching hospital. Int J Pharm Sci Rev Res, 2013; 21(2):308-311.

4. Kinjal P, Mira D, Samidh S, Jigar P, Kapadia J, Dikshit R. An analysis of serious adverse drug reactions at a tertiary care teaching hospital. Perspect Clin Res 2016; 7(4):81-86.

5. Ramanath KV, Ramesh.S. A study on assessment of Adverse Drug Reactions in Tuberculosis patients. American Journal of Pharmtech Research, 2012; 2(2):584-592.

6. KapadiaVishakha, K. and Tripathi Sanjay, B. (2013) Analysis of 63 Patients of MDR TB on DOTS Plus regimen: An LG Hospital, TB Unit, Ahmedabad Experience. Gujarat Medical Journal, 68, 52-57.

7. Patil SV, Bhagwat RV, Mohite RV, Barphe SS. Profile of adverse drug reactions in multiple drug resistant 
tuberculosis patients at drug resistanttuberculosis center - Miraj, Maharashtra. Int J Med Sci Public Health 2017;6(5):853-858.

8. Rathod KB, Borkar MS, Lamb AR, Suryavanshi SL, Surwade GA, Pandey VR. Adverse events among patients of multi drug resistant tuberculosis receiving second line anti $\mathrm{TB}$ treatment. Int $\mathrm{J}$ Sci Rep 2015;1(6):253-7

9. Dr. Vardhan A, Dr. Gupta A, Dr. Sehgal V.K, Dr. Kansal AP, and Dr. K. Sudesh Adverse drug reactions due to anti tubercular drugs in patients of multidrug resistant tuberculosis in Rajindra hospital Patiala World Journal of Pharmaceutical Research Vol 5, Issue 4, 2016. 1206.

10. Akshata JS, Chakrabarthy A, Swapna R, Buggi S, Somashekar M. Adverse drug reactions in management of multi drug resistant tuberculosis, in tertiary chest institute. Journal of Tuberculosis Research. 2015 Apr 16;3(02):27.

11. Neeta PN, Prashanth N, Ramaprasad G, Gangadhar Goud T, Sameena ARB. A study on outcome of standardized treatment in multidrug resistance tuberculosis patients. Int $\mathrm{J}$ Community Med Public Health 2016;3:257-63.

12. Zala AC, Manvar R, Patel D, Patel D, Gamit N. A prospective-observational study to assess the prevalence of adverse drug reactions in MDR-TB patients at tertiary care hospital in India. American Journal of Pharmacology and Pharmacotherapeutics.2015; 2(4):112-9.

13. Shinde MP, Halasawadekar NR, Ramanand SJ, Pore SM, Ramanand JB, Patil PT, Kumbhar AV. A study of adverse drug reactions in patients receiving treatment for multi-drug resistant tuberculosis. International Journal of Basic \& Clinical Pharmacology. 2017 Jan 28;6(2):354-8. 